\title{
Alelopatia de extratos aquosos de canela-sassafrás (Ocotea odorifera (Vell.) Rohwer)
}

\author{
Flávia Maria da Silva Carmo ${ }^{1,4}$, Eduardo Euclydes de Lima e Borges² e Massanori Takaki ${ }^{3}$
}

\author{
Recebido em 17/04/2006. Aceito em 19/01/2007
}

\begin{abstract}
RESUMO - (Alelopatia de extratos aquosos de canela-sassafrás (Ocotea odorifera (Vell.) Rohwer)). Estudos de alelopatia investigam os efeitos positivos e negativos que metabólitos secundários de plantas, microrganismos ou fungos exercem sobre o desenvolvimento de indivíduos vizinhos. Nesse trabalho foram investigados os efeitos de extratos aquosos de folhas, cascas de tronco e cascas de raízes de canela-sassafrás (Ocotea odorifera (Vell.) Rowher) sobre a germinabilidade das sementes, desenvolvimento do sistema radicular e da parte aérea, teor de clorofila da parte aérea e respiração das células radiculares de plântulas de sorgo (Sorghum bicolor L. Moench cv. Embrapa BR 303). Os extratos foram preparados adicionando o material vegetal seco e moído oriundo de cada órgão à água destilada e deionizada na proporção 1:10 (p/v). Após agitação constante por $24 \mathrm{~h}$, as soluções foram decantadas e filtradas através de papel de filtro sob vácuo, constituindo os extratos testados. Os extratos aquosos de cascas de tronco e de raízes causaram inibição do desenvolvimento do sistema radicular das plântulas de sorgo e a sua parte aérea teve o crescimento estimulado pelo extrato de cascas de raízes. Os extratos de folhas e de cascas de tronco induziram aumento da biomassa fresca do sistema radicular e diminuição significativa do teor de clorofila. Todos os extratos causaram efeitos negativos sobre a respiração radicular das plântulas de sorgo. Concluiu-se que metabólitos secundários da canela-sassafrás causaram alterações metabólicas e morfológicas nas plantas de sorgo e que, portanto, a presença de canela-sassafrás no ambiente pode desencadear efeitos similares sobre outras espécies vegetais na sua vizinhança.
\end{abstract}

Palavras-chave: clorofila, compostos fenólicos, Lauraceae, respiração radicular, terpenos

ABSTRACT - (Allelopathy of Brazilian sassafras (Ocotea odorifera (Vell.) Rohwer) aqueous extracts). Allelopathic studies investigate the positive and negative effects of secondary metabolites of plants, microorganisms and fungi on the development of neighboring individuals. In this work, the allelopathic effects of aqueous extracts of leaves, bark and root bark of Brazilian sassafras (Ocotea odorifera (Vell.) Rowher) on seed germination, root and shoot growth, chlorophyll content and respiratory activity of the root cells of sorghum seedlings (Sorghum bicolor (L) Moench cv. Embrapa BR 303) were analyzed. The extracts were prepared by adding dried, powdered plant material to distilled non-ionized water at 1:10 (w/v). After continuous agitation for $24 \mathrm{~h}$, these solutions were decanted and vacuum-filtered through filter paper, thus constituting the tested extracts. Bark and root bark aqueous extracts caused root growth inhibition in sorghum seedlings while shoot growth was stimulated by the root bark extract. Leaf and bark extracts induced an increase in wet root biomass and a decrease in chlorophyll content. All extracts caused negative effects on sorghum seedling root cell respiration. We concluded that secondary metabolites from Brazilian sassafras caused metabolic and morphological alterations in the sorghum seedlings and the presence of these plants in the environment can cause similar effects on other neighboring plant species.

Key words: chlorophyll, phenolic compounds, Lauraceae, root cell respiration, terpenoids

\section{Introdução}

A alelopatia é definida como qualquer processo envolvendo metabólitos secundários produzidos por plantas, microrganismos e fungos que, uma vez liberados no ambiente, influenciam o crescimento e o desenvolvimento de sistemas biológicos naturais ou implantados, seja de forma positiva ou negativa. Certamente, nenhuma área de investigação dentro da biologia vegetal tem provocado tanta controvérsia quanto a ciência da alelopatia (Romeo \& Weidenhamer 1998).

Embora de escopo amplo, as investigações científicas em alelopatia têm se concentrado principalmente nas interações entre espécies vegetais cultivadas e na prospecção de novas moléculas com propriedades herbicidas. No âmbito das ciências florestais e da ecologia, persiste a escassez de conhecimentos relativos ao comportamento alelopático de espécies arbóreas nativas, ameaçadas ou não de

\footnotetext{
1 Universidade Federal de Viçosa, Departamento de Biologia Vegetal, 36570-000 Viçosa, MG, Brasil

2 Universidade Federal de Viçosa, Departamento de Engenharia Florestal, 36570-000 Viçosa, MG, Brasil

3 Universidade Estadual Paulista Júlio de Mesquita Filho - UNESP, Instituto de Biociências, Departamento de Botânica, 13506-900 Rio Claro, SP, Brasil

4 Autor para correspondência: fmcarmo@ufv.br
} 
extinção, e aquelas com potencial para utilização em reflorestamentos, plantios mistos e sistemas agroflorestais e agrossilvopastoris (Anaya 1999). Dentro do conjunto dos conhecimentos atuais acerca das espécies com potencialidades alelopáticas, existe ainda uma lacuna no que tange aos efeitos das substâncias alelopáticas sobre o metabolismo das espécies alvo (Reigosa et al. 1999; Mizutani 1999; Inderjit \& Duke 2003).

Ocotea odorifera (Vell.) Rowher, Lauraceae, conhecida como canela-sassafrás, é uma espécie arbórea nativa do Brasil e naturalmente encontrada nos domínios da Mata Atlântica, do Rio Grande do Sul até o sul da Bahia. É utilizada para a recuperação de matas ciliares degradadas e como árvore madeireira, é considerada de regeneração artificial problemática (Carvalho 1994). É reconhecida fitoquimicamente pela síntese de flavonóides, como o canferol e a quercetina, polipropanóides, esteróides, sesquiterpenos e óleos essenciais (Costa 2000; Lordello et al. 2000; Watson \& Dallwits 2005). Dentre os componentes desse óleo essencial está o safrol, uma substância comercializada no mundo inteiro e utilizada em vários ramos industriais, pelo qual milhares de indivíduos de canela-sassafrás foram sacrificados nas matas do sul do País até a década de 1990, levando a espécie a ser incluída na lista oficial de espécies ameaçadas de extinção (Portaria IBAMA n ${ }^{\circ}$ 6-N, de 15 de janeiro de 1992) e à conseqüente proibição de seu corte a partir de então.

A canela-sassafrás (Ocotea. odorifera) é considerada uma espécie que exerce efeito alelopático, inibindo o desenvolvimento tanto da parte aérea quanto do sistema radicular das plantas submetidas aos seus extratos (Borges et al. 1993). A diversidade de espécies vegetais sob as copas dos indivíduos dessa espécie é baixa, da mesma forma que sua freqüência de regeneração natural (Cetnarski Filho \& Nogueira 2005).

Dada a importância econômica e ecológica dessa espécie, os objetivos deste trabalho foram detectar interferências dos extratos preparados a partir de seus tecidos no padrão de germinação, desenvolvimento inicial das plântulas, teor de clorofila e atividade respiratória das células radiculares do sorgo (Sorghum bicolor (L.) Moench cv. Embrapa BR 303).

\section{Material e métodos}

Foram coletadas folhas verdes e recém caídas, cascas de tronco e de raízes de indivíduos adultos de canela-sassafrás. As cascas dos troncos e das raízes foram obtidas em lascas, por meio de incisões com aproximadamente $2 \mathrm{~cm}$ de profundidade. Quando as raízes eram finas (até $\pm 3 \mathrm{~cm}$ de diâmetro), estas foram utilizadas inteiras. Tanto para as cascas de tronco como para as cascas de raízes, foram utilizados tecidos mortos e vivos, uma vez que a espessura dos cortes abrangeu a casca externa, de tecidos mortos, e a casca interna, de tecidos vivos (periderme, córtex e floema secundário).

O material vegetal oriundo de cada órgão foi seco em estufa com circulação de ar forçado a $45^{\circ} \mathrm{C}$ (Melo et al. 2004) e triturado em moinho de faca com peneira de $1 \mathrm{~mm}$ de diâmetro. Os pulverizados obtidos foram adicionados à água destilada e deionizada na proporção de $1: 10(\mathrm{p} / \mathrm{v})$ e as suspensões permaneceram sob agitação constante por $24 \mathrm{~h}$. Após a decantação, as soluções obtidas foram passadas através de papel de filtro sob vácuo, constituindo três tipos de extratostratamento.

Cada extrato foi avaliado individualmente quanto ao $\mathrm{pH}$, utilizando um pHmetro digital (Hanna Instruments), e quanto ao potencial osmótico, com a utilização de um osmômetro automático (Osmotte A) e padrões 100 e 500 , em três amostras de $2 \mathrm{~mL}$ de cada extrato a $20^{\circ} \mathrm{C}$. Os valores obtidos em mosmol $\mathrm{kg}^{-1}$ de $\mathrm{H}_{2} \mathrm{O}$ foram transformados em MPa.

Sorghum bicolor L. cv. Embrapa BR 303 foi utilizado como espécie-teste ou receptora e as sementes foram obtidas na Embrapa Milho e Sorgo de Sete Lagoas, MG. O bioensaio foi montado em placas de Petri $(\varnothing 10 \mathrm{~cm})$ forradas com duas camadas de papel de filtro umedecidas com $4 \mathrm{~mL}$ de extrato, sobre as quais foram semeadas 20 sementes de sorgo. Nas placas de Petri destinadas ao tratamento controle o papel de filtro foi umedecido com água destilada.

Todos os tratamentos, discriminados pelo tipo de extrato, foram constituídos por cinco repetições, distribuídas inteiramente ao acaso em câmara úmida de germinação tipo B.O. D, a $25^{\circ} \mathrm{C}$, sob iluminação constante, mantida por oito lâmpadas brancas fluorescentes (Osram) de 25W, do tipo luz do dia (a irradiância média de duas lâmpadas desse tipo é igual a $30 \pm 5 \mu \mathrm{mol} . \mathrm{m}^{2} . \mathrm{s}^{-1}$, segundo Bravin et al. $2006 \mathrm{e}$ Bravin \& Valentin 2002). O bioensaio foi conduzido por quatro dias, ao fim dos quais foi avaliada a porcentagem de germinação, o crescimento da parte aérea e do sistema radicular, a massa da matéria fresca e seca de cada parte da planta, teores de clorofila e atividades respiratórias potenciais das raízes.

Foram consideradas germinadas as sementes que produziram raiz primária com pelo menos $2 \mathrm{~mm}$ de comprimento, com curvatura geotrópica. $\mathrm{O}$ crescimento 
das plântulas foi avaliado por meio de medidas da parte aérea e do sistema radicular. A biomassa vegetal foi avaliada a fresco e após secagem em estufa com circulação de ar forçado a $45^{\circ} \mathrm{C}$ até massa constante.

Os teores de clorofila foram obtidos após a maceração das partes aéreas das plantas em almofariz e extração com acetona $80 \%$ (Cayon et al. 1990). As absorbâncias das soluções cetônicas contendo clorofila foram lidas em espectrofotômetro Perkin Elmer, nos comprimentos de onda de 645 e $663 \mathrm{~nm}$ e, a partir desses dados, foram calculados os teores de clorofila a, de clorofila b e de clorofila total (Arnon 1949).

A respiração potencial das células radiculares das plântulas de sorgo foi estimada por meio da redução do cloridrato de trifenil tetrazólio (TTC) pela atividade de enzimas desidrogenase e do surgimento do formazan. Para a avaliação dessa característica as raízes foram cortadas a $1 \mathrm{~cm}$ a partir da coifa, sendo tomadas as suas massas e em seguida transferidas para tubos de ensaio de $17 \times 120 \mathrm{~mm}$, onde foram adicionados $3 \mathrm{~mL}$ de cloridrato de trifenil tetrazólio (TTC) $0,6 \%$ (p/v) em tampão fosfato $0,05 \mathrm{M}(\mathrm{pH} 7,0)$. Os tubos de ensaio foram mantidos sob vácuo em dessecadores, por 2 horas, sendo posteriormente transferidos para manho-maria a $30{ }^{\circ} \mathrm{C}$ por 15 horas. Ao final desse tempo, as soluções de TTC foram drenadas dos tubos de ensaio e as raízes foram lavadas uma vez em água destilada, que em seguida também foi drenada ao máximo. Os tubos de ensaio contendo as raízes foram novamente transferidos para o banhomaria com água fervente $\left( \pm 100{ }^{\circ} \mathrm{C}\right)$, sendo então adicionados $7 \mathrm{~mL}$ de etanol $95 \%$ (v/v) em cada um deles. Decorridos 10 min., as soluções etanólicas obtidas foram drenadas para outros tubos de ensaio. Após o resfriamento à temperatura ambiente, cada solução foi acrescida de $10 \mathrm{~mL}$ de etanol 95\% (v/v). As absorbâncias dessas soluções etanólicas foram lidas em espectrofotômetro Perkin Elmer, no comprimento de onda de $530 \mathrm{~nm}$ (Steponkus \& Lanphear 1967).
Os dados foram tratados estatisticamente por meio de análises de variância (ANOVA) e pelo teste $F$ com contraste de médias, depois de testadas a normalidade e a homogeneidade dos dados, a 1\% de significância estatística, conforme as características do conjunto de dados, utilizando o programa $\mathrm{R}$ (R Development Core Team 2005).

\section{Resultados}

As avaliações do pH e do potencial osmótico dos extratos mostraram diferenças significativas em relação à água (Tab. 1). Os extratos de canela-sassafrás reduziram significativamente a germinabilidade das sementes de sorgo em relação ao controle (Fig. 1).

Todos os extratos de canela-sassafrás causaram diminuição do crescimento do sistema radicular e os maiores efeitos foram verificados nas plântulas submetidas aos extratos de cascas de tronco e de raízes. O crescimento da parte aérea também foi afetado por todos os extratos, porém, os de folhas e de cascas de tronco por inibição e os de raízes por estímulo do seu crescimento (Fig. 2). Os extratos de folhas e de cascas de tronco causaram aumento da massa a fresco do sistema radicular das plântulas de sorgo, em relação às plântulas sob o tratamento controle e sob a ação dos extratos de raízes. As massas a fresco da parte aérea das plântulas de sorgo não foram afetadas pelos extratos de canela-sassafrás (Fig. 3). Tanto o sistema radicular quanto a parte aérea das plântulas de sorgo apresentaram redução de massa da matéria seca sob os tratamentos com os diversos extratos de canelasassafrás, quando comparados com as plântulas do tratamento controle (Fig. 3).

Os extratos de canela-sassafrás oriundos de folhas e de cascas de tronco inibiram a produção de clorofila das plântulas de sorgo (Fig. 4). As absorbâncias lidas para as soluções obtidas das raízes das plântulas de sorgo sob os tratamentos com extratos de canela-

Tabela 1. Valores médios e desvios padrão de $\mathrm{pH}$ e potencial osmótico dos extratos aquosos 1/10 (p/v) de canela-sassafrás (Ocotea odorifera (Vel.) Rowher).

\begin{tabular}{lccc}
\hline & $\mathrm{pH}$ & mosmol/L & MPa \\
\hline Controle (água destilada) & $6,8 \pm 0,2164 \mathrm{a}$ & 0,080 & $0,000195 \pm 0,000024 \mathrm{a}$ \\
Extrato de folhas & $5,49 \pm 0,0700 \mathrm{~b}$ & 11,667 & $0,028432 \pm 0,000613 \mathrm{~b}$ \\
Extrato de cascas & $5,78 \pm 0,01250 \mathrm{~b}$ & 13,633 & $0,033224 \pm 0,000613 \mathrm{~b}$ \\
Extrato de raízes & $5,67 \pm 0,0057 \mathrm{~b}$ & 12,500 & $0,030463 \pm 0,000731 \mathrm{~b}$ \\
\hline
\end{tabular}

Médias seguidas por letras iguais na vertical não diferem entre si $(P \leq 0,01)$. 


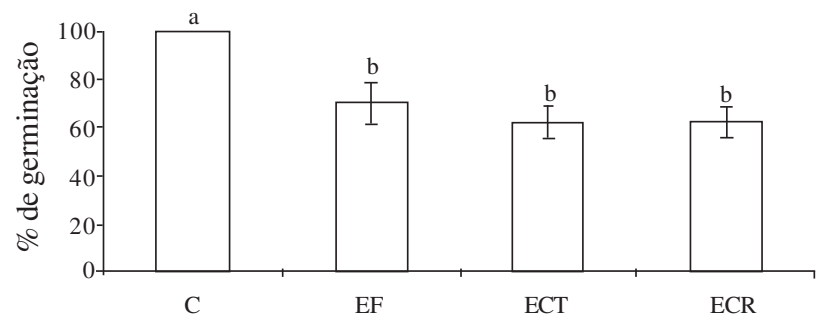

Figura 1. Porcentagem média de germinação de sementes de sorgo (Sorghum granifero (L.) Moench cv. Embrapa BR 303), sob tratamento com extratos $1 / 10(\mathrm{p} / \mathrm{v})$ de canela-sassafrás (Ocotea odorifera (Vel.) Rowher). As barras que apresentam a mesma letra não diferem estatisticamente entre si $(P \leq 0,01) . \mathrm{C}=$ água destilada; $\mathrm{EF}=$ extrato de folhas; $\mathrm{ECT}=$ extrato de cascas de troncos; $\mathrm{ECR}=$ extrato de casca de raízes.

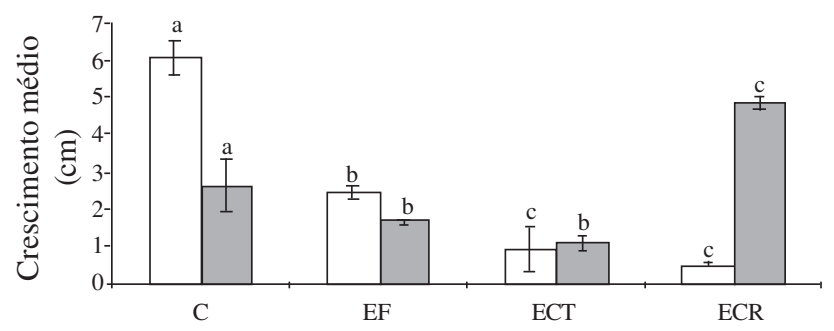

Figura 2. Crescimento médio do sistema radicular e da parte aérea de plântulas de sorgo (Sorghum granifero (L.) Moench cv. Embrapa BR 303), sob tratamento com extratos $1 / 10$ (p/v) de canela-sassafrás (Ocotea odorifera (Vel.) Rowher). As barras com mesmo padrão de preenchimento e a mesma letra não diferem estatisticamente entre si $(P \leq 0,01) . \mathrm{C}=$ água destilada; $\mathrm{EF}=$ extrato de folhas; $\mathrm{ECT}=$ extrato de cascas de troncos; $\mathrm{ECR}=$ extrato de casca de raízes. $\square=$ Sistema radicular; $\square=$ Parte aérea.



Figura 3. Massas (mg) médias obtidas a fresco e a seco do Sistema Radicular (SR) e da Parte Aérea de plântulas de sorgo (Sorghum granifero (L.) Moench cv. Embrapa BR 303), sob tratamento com extratos 1/10 (p/v) de canela-sassafrás (Ocotea odorifera (Vel.) Rowher). As barras com mesmo padrão de preenchimento e a mesma letra não diferem estatisticamente entre si $(P \leq 0,01)$. $\mathrm{C}=$ água destilada; $\mathrm{EF}=$ extrato de folhas; $\mathrm{ECT}=$ extrato de cascas de troncos; $\mathrm{ECR}=$ extrato de casca de raízes. $\square=\mathrm{SR}$ - fresca; $\square$ = SR - seca; $\square$ = PA - fresca; $\square$ = PA - seca.



Figura 4. Teor médio de clorofila total na parte aérea de plântulas de sorgo (Sorghum granifero (L.) Moench cv. Embrapa BR 303), sob tratamento com extratos $1 / 10(\mathrm{p} / \mathrm{v})$ de canela-sassafrás (Ocotea odorifera (Vel.) Rowher). As barras com a mesma letra não diferem estatisticamente entre si $(P \leq 0,01) . \mathrm{C}=$ água destilada; $\mathrm{EF}=$ extrato de folhas; $\mathrm{ECT}=$ extrato de cascas de troncos; $\mathrm{ECR}=$ extrato de casca de raízes.

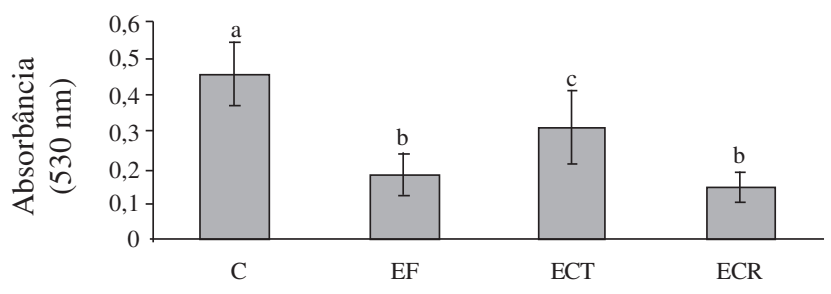

Figura 5. Respiração potencial (síntese de formazan pela atividade de enzimas desidrogenases) nas raízes de plântulas de sorgo (Sorghum granifero (L.) Moench cv. Embrapa BR 303), sob tratamento com extratos 1/10 (p/v) de canela-sassafrás (Ocotea odorifera (Vel.) Rowher). As barras com a uma mesma letra não diferem estatisticamente entre si $(P \leq 0,01) . \mathrm{C}=$ água destilada; $\mathrm{EF}=$ extrato de folhas; $\mathrm{ECT}=$ extrato de cascas de troncos; $\mathrm{ECR}=$ extrato de casca de raízes.

sassafrás exibiram menores valores em comparação com o controle, mostrando que todos os extratos inibiram a atividade respiratória das células das raízes das plântulas (Fig. 5).

\section{Discussão}

As respostas fisiológicas e morfológicas das sementes ou das plântulas à exposição a compostos alelopáticos são manifestações secundárias decorrentes de alterações moleculares e celulares, cujos mecanismos ainda permanecem obscuros (Ferreira \& Áquila 2000). Da mesma forma, o perfil químico da maioria das espécies testadas em bioensaios de alelopatia também não está disponível na literatura. Assim, a caracterização físico-química dos extratos vegetais utilizados nesses bioensaios é importante para que se possa concluir a respeito dos efeitos biológicos observados. 
Dentre essas características, a avaliação do $\mathrm{pH}$ e do potencial osmótico dos extratos vegetais é fundamental quando se desconhece sua constituição em açúcares, aminoácidos, ácidos orgânicos, íons e outras moléculas, pois valores extremos tanto de $\mathrm{pH}$ quanto de potencial osmótico dos extratos podem atuar sobre as sementes e/ou plântulas e mascarar o efeito alelopático (Ferreira \& Aquila 2000). No caso presente, tanto o pH quanto o potencial osmótico dos extratos foram encontrados dentro de uma faixa de valores aceitáveis como não interferentes sobre a germinabilidade das sementes de sorgo, conforme dados de Carvalho et al. (2000) e Medeiros-Filho et al. (2000).

A inibição da germinação das sementes de outras plantas, além das de sorgo, por extratos de canelasassafrás, já foi relatada na literatura (Borges et al. 1993; Carmo 2002), corroborando os dados obtidos neste trabalho e confirmando a sensibilidade das sementes aos compostos alelopáticos extraídos desta espécie arbórea.

Os bionsaios de germinação de sementes na presença de extratos vegetais são pontos de partida para a investigação de efeitos de alelopatia intra e interespecíficos, embora haja controvérsia em relação a este tipo de experimento (Anderson \& Loucks 1966; Leather \& Einhellig 1988; Haugland \& Brandsaeter 1996; Hamdi et al. 2001). O argumento é que as sementes, em decorrência de processos seletivos e evolutivos, são menos sensíveis aos aleloquímicos do que as plântulas (Ferreira \& Aquila 2000). Por outro lado, estudos recentes mostram que, embora a porcentagem final de germinação possa não ser significativamente afetada pela ação de aleloquímicos, o padrão de germinação pode ser modificado, verificando-se diferenças na velocidade e na sincronia da germinação de sementes submetidas a tais compostos (Santana et al. 2006). A importância dessa metodologia se deve ao fato de que as sementes constituem unidades biológicas por meio das quais processos ecológicos, como a competição intra e interespecíficas, a invasão de novos nichos por espécies não nativas, a colonização de novos hábitats e a regeneração da vegetação nativa, dentre outros, podem ser desencadeados.

No ambiente, o impedimento da germinação de sementes quimicamente sensíveis a substâncias alelofitotóxicas liberadas por indivíduos da sua própria espécie (autotoxicidade) ou não, pode ter como consequiência a diminuição da densidade de seus indivíduos o que, a médio e longo prazos, pode levar à extinção local dessa espécie, com implicações para a biodiversidade local (Levin 1970; Heywood 1989; Noble 1989; Reigosa et al. 1999; Callaway et al. 2003). Assim, a síntese e a liberação de metabólitos secundários capazes de influenciar negativamente a germinação de sementes ao redor do indivíduo que os produziu é uma estratégia de interferência competitiva robusta, que confere vantagens a esses indivíduos quando encontrados em ambientes naturais; porém, no que tange a estruturação de populações em agroflorestas, consórcios silviculturais e de culturas, pode significar a falência do sistema.

Os resultados obtidos, relativos ao sistema radicular das plântulas de sorgo sob os tratamentos sugerem que, nesse estágio de desenvolvimento, esse compartimento é mais sensível do que a parte aérea aos compostos alelofitotóxicos presentes na canelasassafrás.

Extratos semelhantes de canela-sassafrás reduziram mais drasticamente o desenvolvimento do sistema radicular do que a parte aérea de plantas de alface, embora tenha sido registrada a inibição de ambos os compartimentos dessas plantas-teste (Borges et al. 1993). Tanto no ensaio com a alface quanto com o sorgo, os indivíduos estavam em um estágio de desenvolvimento em que o crescimento do sistema radicular é priorizado; portanto, os efeitos deletérios sobre o metabolismo desse órgão são mais drásticos, uma vez que ele é o alvo primário dos aleloquímicos, principalmente durante o desenvolvimento inicial da planta, que é caracterizado por alto metabolismo e sensibilidade ao estresse ambiental (Cruz-Ortega et al. 1998).

Após estudos de fitoquímica de folhas e de ramos de canela-sassafrás de duas localidades na região de Curitiba, PR, Toledo (2000) afirma que essas partes das plantas estudadas apresentam constituintes químicos da classe dos flavonóides, dos esteróides, dos triterpenos, das saponinas e dos taninos, além de aminogrupos e de óleos essenciais, com altos teores de safrol e de cânfora. A presença de lipídeos, mucilagens, compostos fenólicos, óleo-resina e taninos nas folhas de canela-sassafrás coletadas em Viçosa, MG, foi relatada quando esses órgãos foram submetidos a procedimentos de anatomia e histoquímica (Iarema et al. dados não publicados).

Os fenóis e os terpenos são compostos que estão mais envolvidos nos efeitos alelopáticos de inibição de metabolismo das plantas alvo (Indejit \& Duke 2003). Os compostos fenólicos estão implicados na inibição da germinação de sementes e no estabelecimento de 
plantas em comunidades vegetais . Dentre os terpenos, os monoterpenos, constituintes freqüentes dos óleos essenciais, estão mais correlacionados com os efeitos inibitórios observados em sementes, plantas e microrganismos expostos à sua presença (Rice 1984; Harborne 1980).

Uma vez que tanto terpenos quanto compostos fenólicos foram identificados em diferentes partes de Ocotea odorifera, é possível supor que tais efeitos inibitórios sobre a germinação de plantas e sobre o desenvolvimento do sistema radicular e da parte aérea de espécies teste se devam em grande parte a essas substâncias, o que é corroborado pelos dados de massa fresca e seca, que sugerem que as substâncias extraídas desses compartimentos podem ter atuado sobre a permeabilidade das membranas e/ou sobre o balanço hídrico e a aquisição de nutrientes pelo sistema radicular.

A modificação da permeabilidade das membranas celulares sob efeitos de aleloquímicos é citada por vários autores que também relatam alterações no balanço hídrico de plantas submetidas a extratos vegetais e efeitos sobre a respiração celular (Koeppe 1972; Einhellig et al. 1985; Baziramakenga et al. 1995; Calera et al. 1996; Friebe et al. 1997; Hejl \& Koster 2004).

Vários autores têm reportado que algumas classes de aleloquímicos inibem a fotossíntese por induzir mudanças no conteúdo de clorofila das plantas receptoras (Einhellig \& Kuan 1971; Einhellig \& Rasmussen 1979; Blum \& Rebbeck 1989; Baziramakenga et al. 1994; Chou 1999). A aparência clorótica das plantas seria um sintoma da degradação das moléculas de clorofila ou da inibição da sua síntese, ambos os efeitos mediados por aleloquímicos, que impedem a formação das Mg-porfirinas (Einhellig 1986). Em ambos os casos, esses efeitos lembram a atuação dos herbicidas, como as piridazinonas e imidazolinonas (Duke 1985; Cayon et al. 1990).

Compostos alelopáticos de capim do pomar (Dactylis glomerata L., Poaceae) atuam sobre a fotossíntese de outras plantas, com ação similar a dos herbicidas fluometuron e linuron (Reigosa et al. 1999), enquanto os ácidos fenólicos, as cumarinas, os polifenóis e os flavonóides são apontados como aleloquímicos que atuam como herbicidas inibitórios da fotossíntese, alterando o transporte de elétrons e a fosforilação nos fotossistemas (Rizvi et al. 1992; Durigan \& Almeida 1993).

A respiração celular também pode ser fortemente afetada pela presença de aleloquímicos (Rice 1984;
Reigosa et al. 1999; Ohno 2000) que interferem em várias etapas desse processo em um ou mais níveis, dos quais dependem as respostas observadas (Chon et al. 2000). A juglona, uma naftoquinona isolada das folhas, da casca dos frutos secos e da casca do tronco de indivíduos do gênero Juglans (Juglandaceae), pode reduzir em até $90 \%$ a respiração das raízes de milho, enquanto o macerado de folhas de artemisia (Artemisia tridentata Nutt., Asteraceae) acelera a respiração das células radiculares de pepino, devido à presença de substâncias do grupo das lactonas (Durigan \& Almeida 1993). Portanto, a respiração das células radiculares pode ser aumentada ou diminuída, dependendo da natureza química dos compostos presentes nos extratos vegetais empregados.

Os ácidos fenólicos são potentes aleloquímicos que induzem o aumento da atividade de enzimas oxidativas, tendo como conseqüência final a modificação da permeabilidade das membranas e a formação de lignina, que contribuem para a redução do alongamento radicular (Baziramakenga et al. 1995; Ferrarese et al. 2000). A inibição da expansão foliar e do alongamento das raízes em ervilhas (Pisum sativum L., Leguminosae) e o estímulo ao aparecimento de raízes secundárias em pepino (Cucumis sativus L., Cucurbitaceae) são efeitos relatados para as plantas tratadas com ácido ferúlico (Blum \& Rebbeck 1989; Vaughan \& Ord 1990). Resultados semelhantes foram relatados por Lovett (1982), nos quais as raízes de linhaça (Linum usitatissimum L., Linaceae) tratadas com benzil amina extraída da camelina (Camelina sativa (L.) Crantz, Brassicaceae) apresentaram desenvolvimento radicular precoce, além de uma série de alterações no metabolismo de lipídios e de proteínas.

Sérias anomalias anatômicas e ultra-estruturais são descritas por Cruz-Ortega et al. (1998) para as raízes de feijão (Phaseolus vulgaris L., Leguminosae) e kurodane (Cucurbita ficifolia Bouché, Cucurbitaceae) sob tratamento com aleloquímicos produzidos por Sicyos deppei G. Don (Cucurbitaceae), sugerindo alterações no material genético, na síntese de proteína e de lipídios e na respiração mitocondrial. Também são relatadas modificações no índice mitótico de células radiculares de alface (Lactuca sativa L., Asteraceae) tratadas com extratos alelopáticos de angico vermelho (Anadenanthera peregrina (L.) Speg, Leguminosae, Mimosoideae) (Abreu et al. 2001; Pires et al. 2001) e alterações na atividade enzimática da peroxidase nas raízes em contato com aleloquímicos, em comparação com as raízes das plantas testemunha (Ferrarese et al. 2001; Pires et al. 2001). 
À luz das alterações morfológicas e fisiológicas mencionadas acima, é possível pensar que o metabolismo das plântulas de sorgo em questão foi alterado e que os agentes dessas mudanças afetaram adversamente a atividade respiratória, seja a nível mitocondrial, seja por atuarem sobre as diversas enzimas envolvidas no processo. Independe da resposta respiratória, o efeito foi sempre danoso para a planta receptora, evidenciando que este é um importante mecanismo de ação destas substâncias.

Os resultados obtidos evidenciam que os extratos de canela-sassafrás têm ação inibitória sobre o metabolismo das plantas teste, interferindo na captação da energia luminosa, por diminuir o teor de clorofila, e na liberação dessa energia, armazenada em moléculas orgânicas, para o crescimento, multiplicação e manutenção das células, por interferir na respiração celular. Todos esses são processos metabólicos cruciais para o estabelecimento de qualquer planta.

Concluindo, é possível que os compostos extraídos da canela-sassafrás pela água, principalmente aqueles presentes nas folhas e nas cascas de troncos possam, em condições naturais, eliminar indivíduos que se estabeleçam ao seu redor. Este é um efeito seletivo, baseado na sensibilidade das espécies às substâncias do seu metabolismo secundário onde também pode estar incluído um efeito de autotoxicidade que controla a distribuição dos indivíduos da própria espécie. O mecanismo seletivo parece ser resultante do desbalanço entre fixação do carbono e a respiração celular, o que ainda está por ser confirmado.

\section{Agradecimentos}

Agradecemos ao CNPq, pela bolsa de estudos concedida à primeira autora para o desenvolvimento de sua Tese de Doutorado em Ciências Biológicas (Biologia Vegetal) na UNESP, Campus de Rio Claro, da qual este trabalho é parte integrante; à FAPEMIG, pelo apoio financeiro à execução do projeto 'Avaliação de Substâncias Alelopáticas em Vegetação de Floresta Atlântica'(CAG 1326/95), coordenado pelo segundo autor, cujos resultados estão parcialmente citados neste trabalho e também ao Programa ProDoc/CAPES, que subsidia a primeira autora como Professora Voluntária integrada ao Corpo Docente do Departamento de Biologia Vegetal da Universidade Federal de Viçosa; aos revisores desse trabalho, em especial à Editora de Área de Fisiologia Vegetal, Profa. Dra. Marli Ranal (UFU), pelas contribuições e pela dedicação e responsabilidade na execução do seu trabalho.

\section{Referências bibliográficas}

Abreu, J.C.; Davide, L.C.; Davide, A.C. \& Souza, I.F. 2001. Effects of aqueous extracts of Anadenanthera peregrina (L.) Speg. on seed germination and seedling growth of lettuce (Lactuca sativa L.). Allelopathy Journal 8: 73-78.

Anaya, A.L. 1999. Allelopathy as a tool in the management of biotic resources in agroecosystems. Critical Reviews in Plant Science 18: 697-739.

Anderson, R.C. \& Loucks, O.L. 1966. Osmotic pressure influence in germination tests for antibiosis. Science 152: $771-773$.

Arnon, D.I. 1949. Copper and enzymes in isolated chloroplast. Polyphenoloxidases in Beta vulgaris. Plant Physiology 24: 1-15.

Baziramakenga, R.; Simard, R.R. \& Leroux, G.D. 1994. Effects of benzoic and cinnamic acids on growth, mineral composition and chlorophyl content of soybean. Journal of Chemical Ecology 20: 2821-2833.

Baziramakenga, R.; Leroux, G.D. \& Simard, R.R. 1995. Effects of benzoic and cinnamic acids on membrane permeability of soybean roots. Journal of Chemical Ecology 21: 271-285.

Blum, U. \& Rebbeck, J. 1989. Inhibition and recover of cucumber roots given multiple treatments of ferulic acid in nutrient culture. Journal of Chemical Ecology 15: 917-928.

Borges, E.E.L.; Lopes, E.S. \& Silva, G.F. 1993. Avaliação de substâncias alelopáticas em vegetação de uma floresta secundária. I - árvores. Revista Árvore 17: 69-84.

Bravin, I.C. \& Valentin, Y.Y. 2002. Influência de faores ambientais sobre o desenvolvimento de Hypnea musciformis (Wulfer) Lamouroux (Gigartinales, Rhodophyta. Revista Brasileira de Botânica 25: 467-474.

Bravin, I.C.; Valentin, Y.Y. \& Yokoya, N.S. 2006. Formação de calos e regeneração de segmentos apicais de Hypnea musciformis (Wulfer) Lamouroux (Gigartinales, Rhodophyta): obtenção de culturas axênicas e efeitos da concentração de agar. Revista Brasileira de Botânica 29: $175-182$.

Calera, M.R.; Anaya, A.L. \& Gavilanes-Ruiz, M. 1995. Effect of phytotoxic resin glycoside on activity of HC-ATPase from plasma membrane. Journal of Chemical Ecology 21: 289-287.

Cayon, D.G.; Lopes, N.L.; Oliva, M.A. \& Silva, J.F. 1990. Teores de clorofila e proteína bruta em soja (Glycine $\max ($ L.) Merril) tratada com imazaquin. Revista Brasileira de Fisiologia Vegetal 2: 33-40.

Carmo, F.M.S. 2002. Substâncias alelopáticas de algumas espécies arbóreas nativas do município de Viçosa, MG, Brasil. Tese de Doutorado. UNESP. Rio Claro. SP.

Callaway, R.M.; Ridenour, W.M.; Laboski, T.; Weir,T. \& Vivanco, J.M. 2005. Natural selection for resistance to the allelopathic effects of invasive plants. Journal of Ecology 93: 576-583. 
Carvalho, L.F.; Medeiros Filho, S.; Rossetti, A.G. \& Teófilo, E.M. 2000. Condicionamento osmótico de sementes de sorgo. Revista Brasileira de Sementes 22: 185-192.

Carvalho, P.E.R. 1994. Espécies florestais brasileiras: recomendações silviculturais, potencialidades e uso da madeira. Colombo, Empresa Brasileira de Pesquisa Agropecuária, Centro Nacional de Pesquisas Florestais.

Cetnarski Filho, R. \& Nogueira, A.C. 2005. Influência da temperatura na germinação de diásporos de Ocotea odorifera (Vell.) Rohwer (canela-sassafrás). Ciência Florestal 5: 191-198.

Costa, P.R.R. 2000. Safrol e eugenol: estudo da reatividade química e uso em síntese de produtos naturais biologicamente ativos e seus derivados. Química Nova 23: 357-360.

Chon, S-U.; Coutts, J.H. \& Nelson, C.J. 2000. Effects of light, growth media and seedling orientation on bioassays of alfaa autotoxicity. Agronomy Journal 92: 715-720.

Chou, C.H. 1999. Roles of allelopathy in plant biodiversity and sustainable agriculture. Critical Reviews in Plant Science 18: 609-636.

Cruz-Ortega, R.; Anaya, A.L.; Hernández, B.E. \& Laguna, G. 1998. Effects of allelochemical stress produced by Sicyos deppei on seedling root ultraestructure of Phaseolus vulgaris and Cucurbita ficifolia. Journal of Chemical Ecology 24: 2039-2057.

Duke, S.O. 1985. Effects of herbicide on nonphotosynthetic biosynthetic process. Pp. 91-112. In: S.O. Duke (ed.) Weed Physiology. Vol. II. Boca Raton, CRC Press.

Durigan, J.C. \& Almeida, F.L.S. 1993. Noções sobre alelopatia. Jaboticabal, FUNEP.

Einhellig, F.A. 1986. Mechanisms and modes of action of allelochemicals. Pp. 171-188. In: A.R. Putnam \& C.H.-S. Tang (eds.). The Science of Allelopathy. Nova York, John Wiley and Sons.

Einhellig, F.A.; Muth, M.S. \& Schon, M.K. 1985. Effects of allelochemicals on plant-water relationships. Pp. 179-195. In: A.C. Thompson (ed.). ACS Symposium Series 268. New York, American Chemical Society.

Einhellig, F.A. \& Kuan, L. 1971. Effects of scolpoletin on growth, $\mathrm{CO}_{2}$ exchange rates, and concentration of scopoletin, scopolin and chlorogenic acids in tobacco, sunflower and pigweed. Bulletin Torrey Botanical Club 98: $155-162$.

Einhellig, F.A. \& Rasmussen, J.A. 1979. Effects of tree phenolics acids on chlorophyll content and growth of soybean and grain sorghum. Journal of Chemical Ecology 5: 815-24.

Ferrarese, M.L.L.; Souza, N.E.; Rodrigues, J.D. \& Ferrarese Filho. 2000. Ferulic acid uptake by soybean root in nutrient culture. Acta Physiologiae Plantarum 22: 121-124.

Ferrarese, M.L.L.; Souza, N.E.; Rodrigues, J.D. \& Ferrarese Filho, O. 2001Carbohydrate and lipid status in soybean roots influenced by ferulic acid uptake. Acta Physiologiae Plantarum 23: 421-427.

Ferreira, A.G. \& Aqüila, M.E.A. 2000. Alelopatia, uma área emergente da ecofisiologia. Revista Brasileira de Fisiologia Vegetal 12 (edição especial): 175-204.
Friebe, A.; Roth U.; Kuck P.; Schnabl, H. \& Schulz M. 1997. Effects of 2-4-dihydroxy-1,4-benzoxazin-3-ones on the activity of plasma membrana $\mathrm{H}^{+}$ATPase. Phytochemistry 44: 979-983.

Hamdi, A.B. 2001. Laboratory bioassays for phytotoxicity: an exemple from wheat straw. Agronomy Journal 93: 43-48.

Harborne, J.B. 1980. Plant phenolics. Pp. 329-395. In: E.A. Bell \& B.V. Charlwood (eds.). Secondary Plant Products. Encyclopaedia of Plant Physiology. v. 8. Berlin, SpringerVerlag. A. Pirson \& M.H. Zimmermann (orgs.).

Haugland, E. \& Brandsaeter, L. 1996. Experiments on bioassay sensitivity in the study of allelopathy. Journal of Chemical Ecology 22: 1845-1859.

Hejl, A.M. \& Koster, K.L. 2004. Juglone disrupts root plasma membrane $\mathrm{H}^{+}$-ATPase activity and impairs water uptake, root respiration, and growth in soybean (Glycine max) and corn (Zea mays). Journal of Chemical Ecology 30: 453-471.

Heiwood, U.H. 1989. Patterns, Extents and modes of invasion by terrestrial plants. Pp. 31-60. In: J.A. Drake et al. (eds.). Biological Invasions: a global perspective. v.37. Paris, SCOPE-John Wiley and Sons.

IBAMA, Instituto Brasileiro de Meio Ambiente. Portaria IBAMA N ${ }^{\circ}$ 6-N, de 15 de janeiro de 1992, Estabelece a Lista Oficial de espécies da Flora Brasileira ameaçadas de extinção. Diário Oficial da União. Brasília, DF, Imprensa Nacional.

Inderjit \& Duke, S. O. 2003. Ecophysiological aspects of allelopathy. Planta 217: 529-539.

Koeppe, D.E. 1972. Some reactions of isolated corn mitochondria influenced by juglone. Physiologia Plantarum 27: 89-94.

Leather, G.R. \& Einhellig, F.A. 1988. Bioassay on naturally occurring allelochemicals for phytotoxicity. Journal of Chemical Ecology 14: 1821-1828.

Levin, S.A. 1970. Community equilibria and stability, and an extension of the competitive exclusion principle. The American Naturalist 104: 413-423.

Lordello, A.L.L.; Cavalheiro, A.J.; Yoshida,M. \& Gottlieb, O.R. 2000. Phenylpropanoids, sterols and sesquiterpene from wood of Ocotea odorifera Lauraceae. Revista Latinoamericana de Química 28: 35-39.

Lovett, J.V. 1982. Allelopathy and self-defense in plants. Australian Weeds 2: 33-35.

Medeiros Filho, S.; Carvalho, L.F.; Teófilo, E.M. \& Rossetti, A.G. 2000. Efeito do osmocondicionamento no vigor de sementes de sorgo. Ciência Agronômica 31(1-2): 33-42.

Melo, E.C.; Radünz, L.L. \& Melo, R.C.A. 2004. Influência do processo de secagem na qualidade de plantas medicinais - Revisão. Engenharia na Agricultura 12: 307-315.

Mizutani, J. 1999. Selected allelochemicals. Critical Reviews in Plant Science 18: 653-671.

Noble, I.R. 1989. Attributes of invaders and the invading process: terrestrial and vascular plants. Pp. 301-313. In: J.A. Drake et al. (eds.). Biological Invasions: a global perspective. v. 37. Paris, SCOPE-John Wiley and Sons. 
Ohno, T. 2000. Phytotoxic effects of red clover amended soils on wild mustard seedling growth. Agriculture, Ecosystems \& Environment 78: 187-92.

Pires, N.M.; Souza, I.R.P.; Prates, H.T.; Faria, T.C.L.; Pereira Filho, I.A. \& Magalhães, P.C. 2001. Efeito do extrato aquoso de leucena sobre o desenvolvimento, índice mitótico e atividade da peroxidade em plântulas de milho. Revista Brasileira de Fisiologia Vegetal 13: 55-65.

Reigosa, M.J.; Sánchez-Moreira, A. \& González, L. 1999. Ecophysiological approach in allelopathy. Critical Reviews in Plant Science 18: 577-608.

Rice, E.L. 1984. Allelopathy. $2^{\text {nd }}$. New York, Academic Press. Rizvi, S.J.H.; Haque, H.; Singh, U.K. \& Rizvi, S.J.H. 1992. A discipline called allelopathy. Pp. 1-10. In: S.J.H. Rizvi \& H. Rizvi (eds.). Allelopathy: Basic and Applied Aspects. Londres, Chapman \& Hall.

Romeo, J.T. \& Weidenhamer, J.D. 1998. Bioassays for allelopathy in terrestrtial plants. Pp.179-211. In: K.F. Haynes \& J.G. Millar (eds.). Methods in Chemical Ecology: bioassay methods. v.2. Massachusetts, Kluwer Academic Publishers.
Santana, D.G.; Ranal, M.A.; Mustafa, C.V. \& Silva, R.M.G. 2006. Germination meansurements to evaluate allelopathic interactions. Allelopathy Journal 17: 43-52.

Steponkus, P.L. \& Lanphear, F.O. 1967. Refinement of the triphenyl tetrazolium chloride method of determining cold injury. Plant Physiology 42: 1423-26.

Toledo, M.G.T. 2000. Estudo botânico e fitoquímico de Ocotea odorifera (Vell.) Rohwer (Lauraceae)da região metropolitana de Curitiba. Dissertação de Mestrado. Curitiba, Universidade Federal do Paraná.

Vaughan, D. \& Ord, B. 1990. Influence of phenolic acids on morphological changes in roots of Pisum sativum. Journal of Science Food and Agricultural 25: 289-99.

Yurconis, K.A.; Meiner, S.J. \& Wachholder, B. E. 2005. Invasion impacts through altered community dynamics. Journal of Ecology 93: 1053-1061.

Watson, L. \& Dallwitz, M.J. 2005. The families of flowering plants: descriptions, illustrations, identification, and information retrieval. (1992 onwards) Version: 13th January 2005. http://delta-intkey.com. http://deltaintkey.com/angio/www/lauracea.htm. (Acesso em: $29 / 06 / 2005$ 